\title{
Novel Intensified Alternatives for Purification of Levulinic Acid Recovered from Lignocellulosic Biomass
}

\author{
Massimiliano Errico ${ }^{1, *(D)}$, Roumiana P. Stateva ${ }^{2}$ and Sébastien Leveneur ${ }^{3}$ (D) \\ 1 Department of Green Technology, Faculty of Engineering, University of Southern Denmark, \\ Campusvej 55, 5230 Odense, Denmark \\ 2 Institute of Chemical Engineering, Bulgarian Academy of Science, 1113 Sofia, Bulgaria; thermod@bas.bg \\ 3 Laboratoire de Sécurité des Procédés Chimiques LSPC, EA4704, INSA Rouen, Normandie University, \\ UNIROUEN, 76800 Saint-Étienne-du-Rouvray, France; sebastien.leveneur@insa-rouen.fr \\ * Correspondence: maer@igt.sdu.dk
}

check for updates

Citation: Errico, M.; Stateva, R.P.; Leveneur, S. Novel Intensified Alternatives for Purification of Levulinic Acid Recovered from Lignocellulosic Biomass. Processes 2021, 9, 490. https://doi.org/ $10.3390 /$ pr9030490

Academic Editor: Fabrizio Scala

Received: 20 February 2021

Accepted: 3 March 2021

Published: 9 March 2021

Publisher's Note: MDPI stays neutral with regard to jurisdictional claims in published maps and institutional affiliations.

Copyright: (c) 2021 by the authors. Licensee MDPI, Basel, Switzerland. This article is an open access article distributed under the terms and conditions of the Creative Commons Attribution (CC BY) license (https:/ / creativecommons.org/licenses/by/ $4.0 /)$.

\begin{abstract}
The development of a bio-based economy has its foundations in the development of efficient processes to optimize biomass potential. In this context there are a multitude of molecules that can be either synthetized or recovered from biomass, among those the so-called 12 buildingblocks reported by the US Department of Energy. Even if their identification and importance is clearly defined, research efforts concerning the purification or separation of these platform molecules are limited. To fill this gap, different configurations for the purification of levulinic acid recovered from lignocellulosic biomass are examined and compared in this work. In particular, hybrid configurations obtained by the combination of liquid-liquid extraction and distillation have been considered. It was demonstrated how a deep understanding of the subspace including all extraction-assisted simple column distillation configurations represents a fundamental step in the synthesis of different process alternatives. From a separation efficiency and economic standpoint, the proposed intensified liquidliquid thermally equivalent configuration (LL-TE) and liquid-liquid side stream column configuration (LL-SSC) are promising solutions. Nonetheless, their performances are deeply interrelated to the purity target defined by the designer.
\end{abstract}

Keywords: process synthesis; process intensification; levulinic acid; separation and purification

\section{Introduction}

The increase of carbon dioxide emissions and fossil raw materials depletion are considered major threats to humanity. The development of modern societies was initially based on the usage of coal, followed by oil and gas. Their conversion to derived-fossil products can be seen everywhere in daily life (cars, textiles, chemicals ... ), and is a result of intense research and development of efficient processes. The high-energy content of non-renewable sources, however, renders their complete substitution challenging or nearly impossible. For years, our societies extracted fossilized-carbon leading to significant and unbalanced carbon emissions. To mitigate this effect, efforts worldwide are now focused on valorizing biomass [1-4], which was the first raw material used by mankind.

Nevertheless, the food crisis in the 2000s demonstrated in full the limits of using first-generation biomass, i.e., food-related biomass [5]. As a result, the focus was set to substantiating new generations of biomass and unlocking its potential. One of the most appealing second-generation biomasses is lignocellulosic wastes and at present their valorization is considered as a new hope for our societies because it avoids the ethical dilemma of food versus fuel. Lignocellulosic biomass is a complex chemical structure comprising three main elements: cellulose, hemicellulose and lignin. The composition of these three elements varies from one species to another and depends on many factors, among which the most important are the plant age, land, and season. The number of chemicals, fuels and materials that can be obtained as a result of the valorization of 
these raw materials is huge, which makes the design of the complete process particularly challenging and requires specific attention to the possible bottlenecks within the pretreatment, fermentation and separation steps.

Several platform molecules can be produced from lignin, cellulose or hemicellulose [6]. Among those, levulinic acid (LA) is already manufactured on an industrial scale, e.g., the Biofine process [7-11]. LA is a multifunctional compound that combines in the same molecule a keto and an acid group giving unique properties as a building-block chemical. LA boasts a vast portfolio of applications including food, agriculture polymer and pharmaceutical $[12,13]$. In particular, it can be used to produce different fuel additives such as $\gamma$-valerolactone, 2-methyltetrahydrofuran, and ethyl levulinate. The molecule $\gamma$ valerolactone is also considered as a platform molecule. These compounds can be blended with petroleum-derived fuels without requiring engine modification [14]. Furthermore, LA was classified by the US Department of Energy as one of the 12 most promising buildingblock molecules in nature. This versatility is certified by the LA market forecast. According to P\&S Intelligence, a market intelligence and consulting firm, the global LA market size was quantified in 27.2 million $\$$ in 2019 with an expected annual growth rate of $8 \%$ in the forecast period 2020-2030 [15].

As discussed by Kumar et al. [16], LA can be produced by synthesis, biological, and extraction routes. The synthesis path includes the use of biomass and follows a step process that includes feedstock pretreatment, hydrolysis of polysaccharides into monosaccharides and acid catalyzed conversion of monosaccharides to LA. Independent of which generation biomass is used-first, second or third-the process includes the same main steps $[17,18]$. The step process reached the industrial implementation with GF Biochemicals leading the way [19].

The bio route is intended for the LA production by fermentation. However, this process is less documented, and it is claimed to be non-effective due to the release of toxic waste materials [20]. Extraction routes are widely explored in the literature since extraction is a very well-established unit operation in the process industry. Different solvents are considered for LA recovery, including traditional chemicals like benzene, $i$-octanol and natural oils as sunflower oil and groundnut oil [20,21].

The principal route for LA production is based on multistep hydrolysis of cellulose or hemicellulose.

The interest in developing efficient ways to produce and separate LA and its derivatives is directly connected to research studies in the field of biotechnology and chemical engineering. These research efforts can be sorted according to the following principal areas:

1. Biomass selection. For processes where biomass is used as a feedstock, its selection is an important issue in the global process economy. Lignocellulosic material [22], oil palm mesocarp fiber [23], and waste fractions from the papermaking process [24] are just a few examples reported in the literature.

2. Development of new catalysts. The acid hydrolysis process is usually used to produce LA with $\mathrm{H}_{2} \mathrm{SO}_{4}$ being the most common acid catalyst [25]. Heterogeneous catalysts are emerging as an alternative to overcome the limitations imposed by the homogeneous counterpart like corrosion and challenge in recovering the catalyst [26-28].

3. Solvent selection for LA extraction. LA extraction from aqueous solutions is the common method for LA production. The definition of the optimal solvent can dictate the economic feasibility of the process. 2-methyltetrahydrofuran [29], phosphine oxide [30], MIBK [30] are a few examples of solvents tested.

4. Analysis of physicochemical and thermodynamic properties of $L A$ and derivatives. This part represents a fundamental step in the definition of properties to be used in the modeling and simulation of the process, particularly because uncertainties in properties values can have a considerable effect on the performance of the thermodynamic models applied to predict and calculate the phase equilibria of the complex systems investigated. Among the different contributions, recently Nikitin et al. [31] reported the experimental values of the critical temperatures, pressures, heat capacities, and ther- 
mal diffusivities of levulinic acid and four n-alkyl levulinates, while Ariba et al. [32] measured and advocated simple relations to express the variation of viscosity, density, refractive index and specific heat capacity for LA and derivatives as a function of temperature.

5. Process simulation and optimization. By using the results achieved in the previous points, process simulation acquires the potential to reduce the gap between research and implementation. It has the benefit to explore different scenarios and optimize the production and separation scheme based on specific objective function(s) [33,34].

There are, however, fewer contributions in the literature devoted to the process of separation for LA production than catalyst or biomass investigation. One such example is the work of Nhien et al. [35]. They proposed a hybrid purification process combining liquid-liquid extraction and distillation for recovery of levulinic acid, furfural (F), and formic acid (FA) from the aqueous mixture obtained in the acidic hydrolysis process of lignocellulosic biomass. The study was recently reconsidered by Alcocer-Garcia et al. [36] in order to include more intensified alternatives and introduce an environmental index together with the economic evaluation. Both studies present important results for the LA separation optimization; still, there is an aspect that has not been considered, namely a complete characterization of the subspace of process alternatives that includes liquid-liquid extraction and ordinary distillation. It is known that different sequences of simple column sequences can be generated depending on the component separation order. To these sequences is associated a different design that leads to a different energy consumption and in general to an economic advantage or disadvantage. This aspect is of paramount importance since it is expected that the optimal simple column sequence generates optimal intensified sequences.

In view of this, the main aim of this work is to investigate the subspace of hybrid liquidliquid extraction combined with ordinary distillation and derive a connection with some intensified alternatives not considered by Nhien et al. [35] and Alcocer-Garcia et al. [36].

Furthermore, the importance of using a proper synthesis methodology in the generation of alternatives screened, and how that impacts the final selection will also be analyzed. The design of all separation sequences was performed by means of the process simulator Aspen Plus V11.

\section{Synthesis Methodology and Generation of the Separation Alternatives}

The combination of liquid-liquid extraction followed by ordinary distillation is an option considered for the separation of different mixtures of bio-alcohols obtained from biomass fermentation. In particular, this solution offers different advantages in dealing with azeotropic mixtures [37,38]. Based on this, Nhien et al. [35], Alcocer-Garcia et al. [36] and Seibert [39] developed a diverse hybrid flowsheet of liquid-liquid extraction and distillation proving the economically convenience of the solution.

In this study, ordinary distillation is intended as a unit operation performed in columns with a single feed and equipped with a condenser and a reboiler associated with the distillate and the residue, respectively. For multicomponent mixtures separated by ordinary distillation, different simple column sequences are possible depending on the component separation order. It is known that simple column sequences are the preferred unit operation used at industrial level [38]. For this reason it is of paramount importance to compare a process alternative proposed with the simple column sequence performing the same separation task. In other words, the subspace that includes all possible simple column sequences is the first to be examined before proceeding with the generation of any other alternative [40].

Before proceeding with the definition of the synthesis procedure to generate process alternatives, it is necessary to examine the mixture properties. It is known that LA does not form an azeotrope with water, FA and F. Still two azeotropes-a minimum heterogeneous azeotrope between water-furfural with a composition of $64.5 \mathrm{wt} . \%$ furfural at $97.8^{\circ} \mathrm{C}$, and a maximum-boiling homogeneous azeotrope between formic acid and water at $106.8^{\circ} \mathrm{C}$ 
are formed. This has an impact on the maximum purity achievable and the way F can be recovered. According to the formula reported by Thompson and King [41] (Equation (1)), for a 4-component mixture, three simple columns are required arranged in 5 possible sequences, as reported in Figure 1.

$$
N_{S C}=\frac{[2(N-1)] !}{N !(N-1) !}
$$

where $N_{S C}$ is the number of possible configurations and $N$ is the number of components.

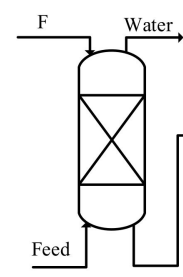

(a)

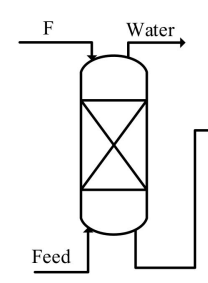

(c)

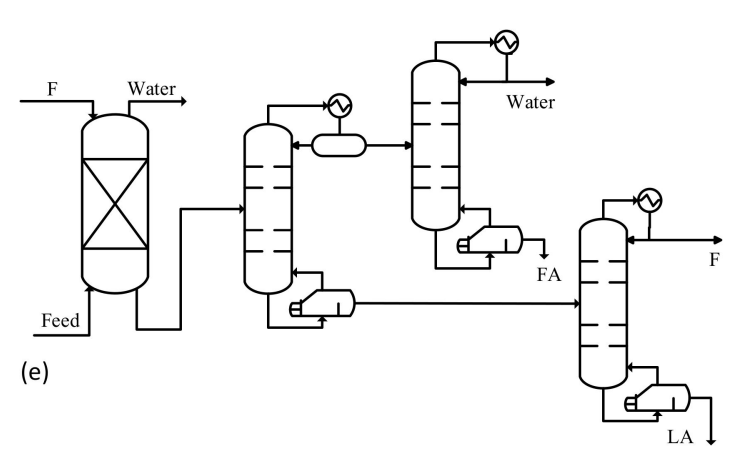

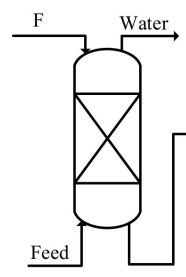

(b)
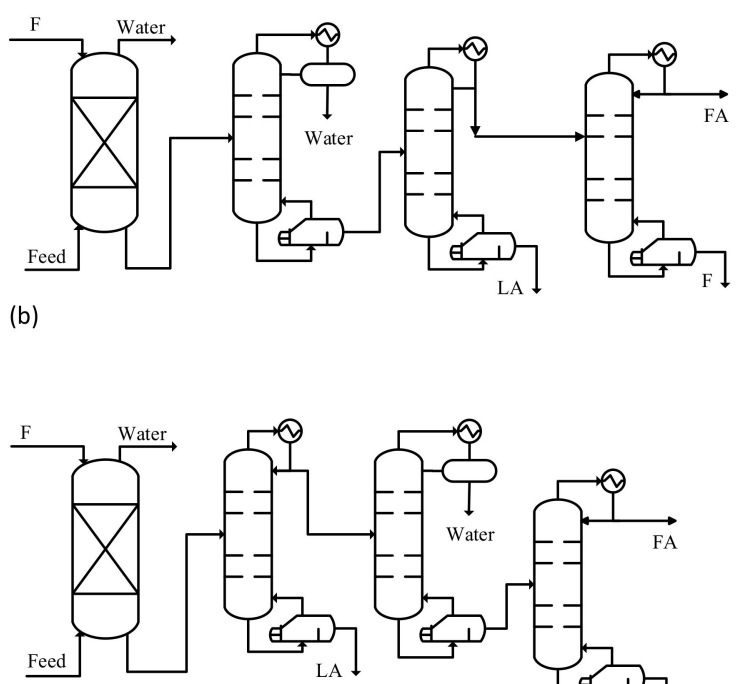

(d)

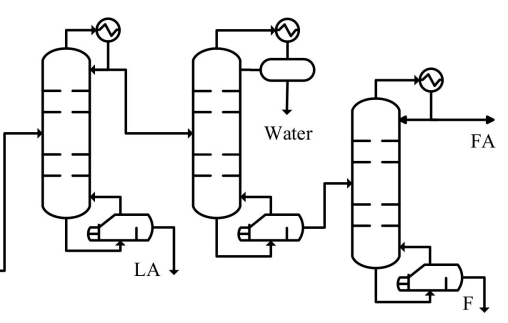

Figure 1. Liquid-liquid (LL) assisted ordinary distillation, (a) LL-assisted direct distillation sequence (LL-D), (b) LL-assisted direct-indirect sequence (LL-DI), (c) LL-assisted indirect sequence (LL-I), (d) LL-assisted indirect-direct sequence (LL-ID), (e) LL-assisted symmetrical sequence (LL-S).

The configurations are named based on the separation order of the products. In the direct configuration (Figure 1a) the products are removed as distillates from the lighter to the heavier. In the indirect configuration (Figure 1c) instead, the components are recovered as bottom streams starting from the heaviest. Mixed configurations like the directindirect (Figure 1b) and the indirect-direct (Figure 1d) are also possible. The symmetrical configuration shown on Figure 1e, in contrast with the previous ones, performs a first separation between the middle components in the first column followed by two columns for the separation of the 4 products.

As shown in Figure 1, the distillation column associated with the separation of the water stream is equipped with a decanter. Its function is to take advantage of the heterogeneous azeotrope between furfural and water and recover a water-rich phase as distillate and recycle the $\mathrm{F}$ rich phase in order to increase its recovery. 
The LL-ID configuration, Figure 1d, was initially considered by Nhien et al. [35], then the configuration LL-D, Figure 1a, was preferred. The authors were motivated in their choice based on the known heuristic rule stating that the direct configuration should be favored [42]. However, following a single heuristic rule does not suffice as it might lead to generating solutions that are not corresponding to the global optimum. For example, if just the heuristic that suggests removing the most plentiful component first is taken into account, then the LL-I configuration of Figure 1c should be preferred. Among all the alternatives Alcocer-Garcia et al. [36] used the LL-ID sequence without decanter as initially proposed by Seibert [39].

The selection of the optimal simple column configuration appears as a fundamental step in the possibility of generating intensified sequences since optimal simple column configuration(s) will generate optimal intensified configurations(s) $[43,44]$.

Starting from a simple column sequence, it is possible to generate thermally coupled configurations by substitution of condenser(s) and/or reboiler(s) associated with non-product streams by a bidirectional stream of liquid and vapor. Thermally coupled configurations can be used to generate thermodynamically equivalent structures by section recombination and then thermodynamically equivalent configurations can generate intensified configurations by eliminating single column sections or implementing single column sections in a divided wall arrangement $[44,45]$. It is easy to imagine how the number of thermally coupled, thermodynamically equivalent and intensified configurations grows if it is necessary to consider all possible alternatives obtainable from each simple column configuration. Hence, screening the subspace of simple column sequences, identifying the optimal one and considering only the alternatives generated from that specific sequence can guide the designer in ascertaining promising solutions without investing computational time in the analysis of all possible configurations [46]. Following this principle, the intensified alternatives are presented after the analysis of the alternatives in Figure 1.

\section{Design Objective and Simulation Settings}

In this study, a model feed with the composition and characteristics reported by Nhien et al. [35] and shown in Table 1 is considered.

Table 1. Feed characterization.

\begin{tabular}{cc}
\hline Component & Mass Fraction [\%] \\
\hline LA & 7 \\
F & 4 \\
FA & 3 \\
Water & 86 \\
Flowrate $\left[\mathrm{kg} \mathrm{h}^{-1}\right]$ & 90,000 \\
Pressure [atm] & 2 \\
Temperature [K] & 298.15 \\
\hline
\end{tabular}

Furfural $(\mathrm{F})$ was chosen as an extracting agent to take advantage of its presence in the initial feed mixture.

The final purity required for LA was fixed at 99\% wt. F was recovered $99.9 \%$ wt pure in order to be recycled to the extractor. The distillation train was designed to achieve a recovery of $\mathrm{F}$ higher than $99.5 \% \mathrm{wt}$. FA purity was set at $85 \%$ wt according to the most common market request [47] and the purity of water was never lower than $90 \% \mathrm{wt}$.

Taking into consideration the very strong non-ideality of the system, the NRTL-HOC (non-random two-liquid-Hayden-O'Connell) fluid package was selected to model the liquid-liquid-vapor phase equilibria. The NRTL-HOC is an asymmetric model in which the vapor phase properties are modeled by the Hayden-O'Connell equation of state (HOC EoS), and those of the liquid phase by NRTL.

The application of HOC EoS requires values for the thermophysical parameters of the four compounds comprising the mixture LA, F, FA and water, e.g., critical parameters, etc. 
In this work the values supplied by the pure compounds library of Aspen Properties were used and a selection of those is reported in Table 2.

Table 2. Pure component parameters retrieved from the Aspen database.

\begin{tabular}{cccc}
\hline & \multicolumn{3}{c}{ Component } \\
\hline Property & LA & FA & F \\
Critical temperature $\left[{ }^{\circ} \mathrm{C}\right]$ & 464.85 & 314.85 & 397.00 \\
Critical pressure $[\mathrm{bar}]$ & 40.02 & 58.10 & 56.60 \\
Critical volume $\left[\mathrm{cm}^{3} \mathrm{~mol}^{-1}\right]$ & 343.00 & 125.00 & 252.00 \\
Acentric factor $[-]$ & 0.755749 & 0.312521 & 0.367784 \\
Standard enthalpy of formation $\left[\mathrm{cal} \mathrm{mol}^{-1}\right]$ & $-144,979$ & $-90,427.10$ & $-36,065.70$ \\
Enthalpy of fusion at melting point $\left[\mathrm{cal} \mathrm{mol}^{-1}\right]$ & 2202.16 & 3033.34 & 3439.38 \\
\hline
\end{tabular}

The binary interaction parameters for the NRTL-HOC model are reported in Table 3. The interaction parameters for LA-FA, LA-Water, and LA-F were estimated with the UNIFAC method.

Table 3. Binary interaction parameters (A, B, C) for the feed components.

\begin{tabular}{ccccccc}
\hline Component $\mathbf{i}$ & Component $\mathbf{j}$ & $\mathbf{A i j}$ & $\mathbf{A j i}$ & $\mathbf{B i j}$ & $\mathbf{B j i}$ & $\mathbf{C i j}$ \\
\hline FA & Water & 4.5156 & -2.5864 & -1432.08 & 725.017 & 0.3 \\
FA & F & 0 & 0 & 46.1655 & 289.216 & 0.3 \\
Water & F & 4.2362 & -4.7563 & -262.241 & 1911.42 & 0.3 \\
LA & FA & 0 & 0 & -337.828 & 569.597 & 0.3 \\
LA & Water & 0 & 0 & -261.319 & 1030.13 & 0.3 \\
LA & F & 0 & 0 & -336.725 & 859.563 & 0.3 \\
\hline
\end{tabular}

The rigorous counter current model "Extract" was used to model the liquid-liquid extraction unit, while "RadFrac" was used for the distillation columns. All columns were optimized with respect to the number of stages, feed location and reflux ratio. The pressure was chosen as the minimum one equal or above the atmospheric value to assure the use of cooling water in the overhead condensers. Pressure drop was neglected, and ideal stages were considered. The temperature of the decanter was optimized to maximize the recovery of $\mathrm{F}$ to be used as a reflux. The distillation columns were considered equipped with total condensers and kettle reboilers.

The different configurations were compared with respect to the operative cost (OC) and the annualized capital costs (ACC). The OC were calculated according to Equation (2).

$$
O C=\sum_{i=1}^{n} C_{i, u t}
$$

where $C_{i, u t}$ is the cost associated to the external utility. The evaluation of the operative costs was implemented directly in the simulation associating each heat exchanger with a proper utility taking into account a minimum temperature difference of $10^{\circ} \mathrm{C}$ between utility and process stream.

Cooling water available at $20^{\circ} \mathrm{C}$, medium pressure steam at $174{ }^{\circ} \mathrm{C}$ and hot oil at 280 ${ }^{\circ} \mathrm{C}$ were used. The energy price for water was $2.12 \times 10^{-7} \$ \mathrm{~kJ}^{-1}$, for the medium pressure steam $2.2 \times 10^{-6} \$ \mathrm{~kJ}^{-1}$, and $3.5 \times 10^{-6} \$ \mathrm{~kJ}^{-1}$ for the hot oil. Moreover, $8760 \mathrm{hr} \mathrm{yr}^{-1}$ were assumed [48].

The annualized capital costs were evaluated according to Guthrier's method [49], annualized considering a payback period of 10 years and actualized to August 2020 considering the Chemical Engineering Plant Cost Index [50]. For each column an extra height of $3 \mathrm{~m}$ for vapor disengagement and to keep a sufficient liquid level on the bottom was considered. Both indexes are regarded as representative of the economy of the process. 


\section{Simulation Results and Novel Intensified Configurations}

In the simulation of the hybrid liquid-liquid extraction assisted ordinary distillation of Figure 1 the recovery of LA in the extractor was fixed at 99\% on mass basis and it was achieved with a solvent to feed ratio of 1.2. Nhien et al. [35] and Alcocer-Garcia et al. [36] considered a purity of LA $98 \%$ wt. while in this study this value was increased to $99 \% \mathrm{wt}$. This increase of purity causes the temperature of the LA stream to reach $253^{\circ} \mathrm{C}$ requiring the use of hot oil as reboiler utility. For this reason, the operative costs of this study are higher than those reported by Nhien et al. [35] and Alcocer-Garcia et al. [36].

For LL-I and LL-S configurations was not possible to reach the purity specification for FA under the limitation of using only cooling water as cold utility. In fact, in order to recover FA in the decanter it would be necessary to decrease the temperature below $40^{\circ} \mathrm{C}$. These configurations are not reported in the results. The OC and ACC are summarized in Figure 2.

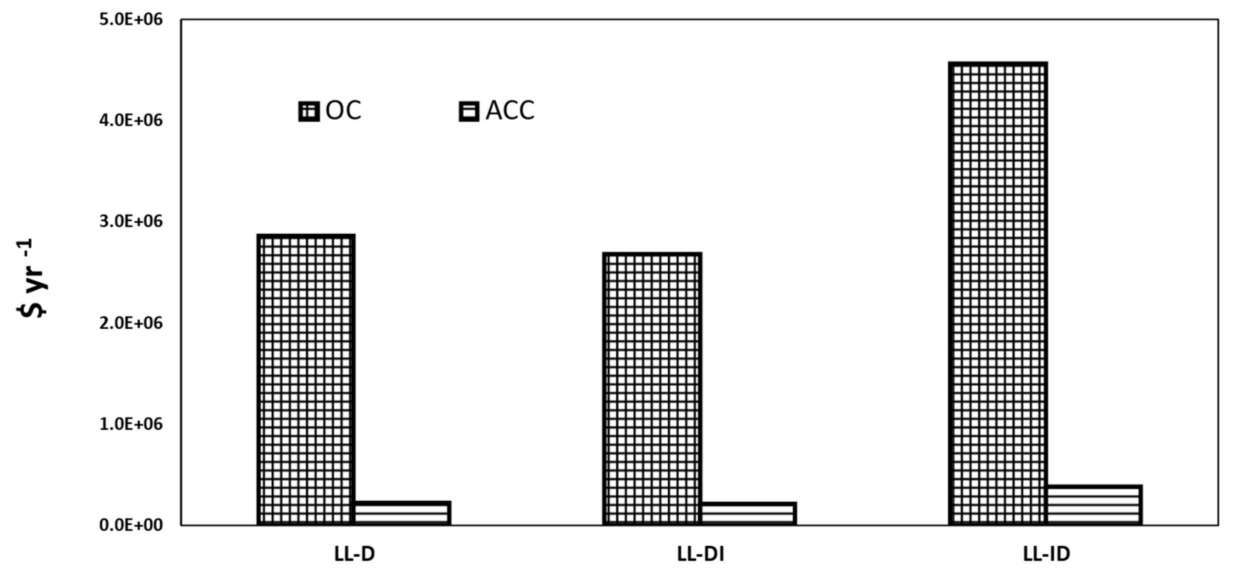

Figure 2. Operative and annualized capital costs for the configurations of Figure 1 reaching the purity targets.

As shown, the best separation alternative in terms of both OC and ACC is the LL-DI. Its operative cost is $6 \%$ lower than that of LL-D considered by Nhien et al. [35].

The design parameters for this configuration are reported in Table 4.

Table 4. Design parameters and operative variables for the configuration LL-DI.

\begin{tabular}{ccccc}
\hline & Extractor & Column 1 & Column 2 & Column 3 \\
\hline Number of stages & 35 & 20 & 22 & 28 \\
Feed stage & - & 11 & 13 & 12 \\
Reflux ratio [mass] & - & 0.5 & - & 48.80 \\
Diameter [m] & - & 2.68 & 3.27 & 1.76 \\
Extract flowrate [kg h $\left.{ }^{-1}\right]$ & 114,069 & - & - & - \\
Residue stream [kg h $\left.{ }^{-1}\right]$ & - & 6270 & 104,330 & 104,010 \\
Distillate temperature [K] & - & 316.15 & 333.15 & 379.29 \\
Residue temperature [K] & - & 530.72 & 432.75 & 434.47 \\
Condenser duty [kW] & - & 2452.31 & $14,729.6$ & 3419.68 \\
Reboiler duty [kW] & - & 9358.43 & $15,005.3$ & 3487.82 \\
\hline
\end{tabular}

Generation of the Intensified Alternatives

Intensified alternatives are intended as configurations with reduced equipment offering the same performance as the traditional configuration but at a reduced energy consumption and capital investment.

Different alternatives can be generated from the LL-DI selected in the previous section as the best performing. It is possible to consider thermally coupled, thermodynamically 
equivalent or sequences with a reduced number of columns. A complete overview was given by Errico et al. [40]. In this work only the configurations in Figure 3 are considered as a possible example.
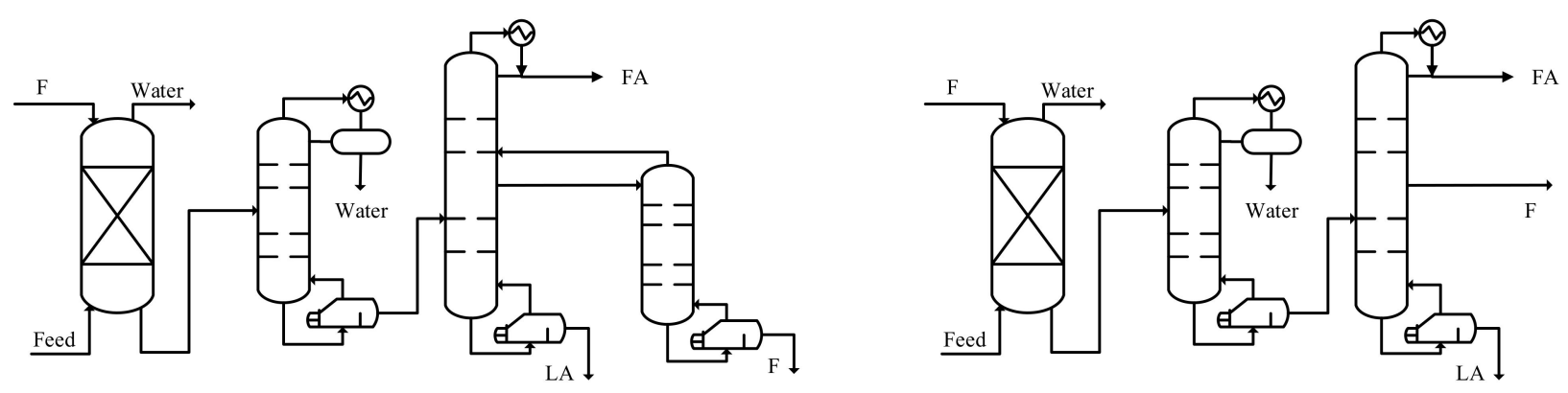

Figure 3. Intensified configurations. (Left): liquid-liquid-thermally equivalent configuration (LL-TE). (Right): liquid-liquid side stream column configuration (LL-SSC).

Starting from the LL-DI configuration, the LL-TE (Figure 3 left) was obtained removing the condenser of the second column and moving the section associated to the FA separation. In this way $\mathrm{F}$ is separated in the rectifying section. The LL-TE configuration can be further intensified by removing the rectifying section and recovering $\mathrm{F}$ as a side stream. The configuration obtained, called LL-SSC (Figure 3 right) has reduced equipment compared to the LL-TE and to the LL-DI from which it is derived.

The configuration parameters and the energy consumption of the two intensified alternatives are summarized in Table 5. The extractor and the first column were not reported since these results are identical to those reported in Table 4.

Table 5. Design parameters and operative variables for the configurations LL-TE and LL-SSC.

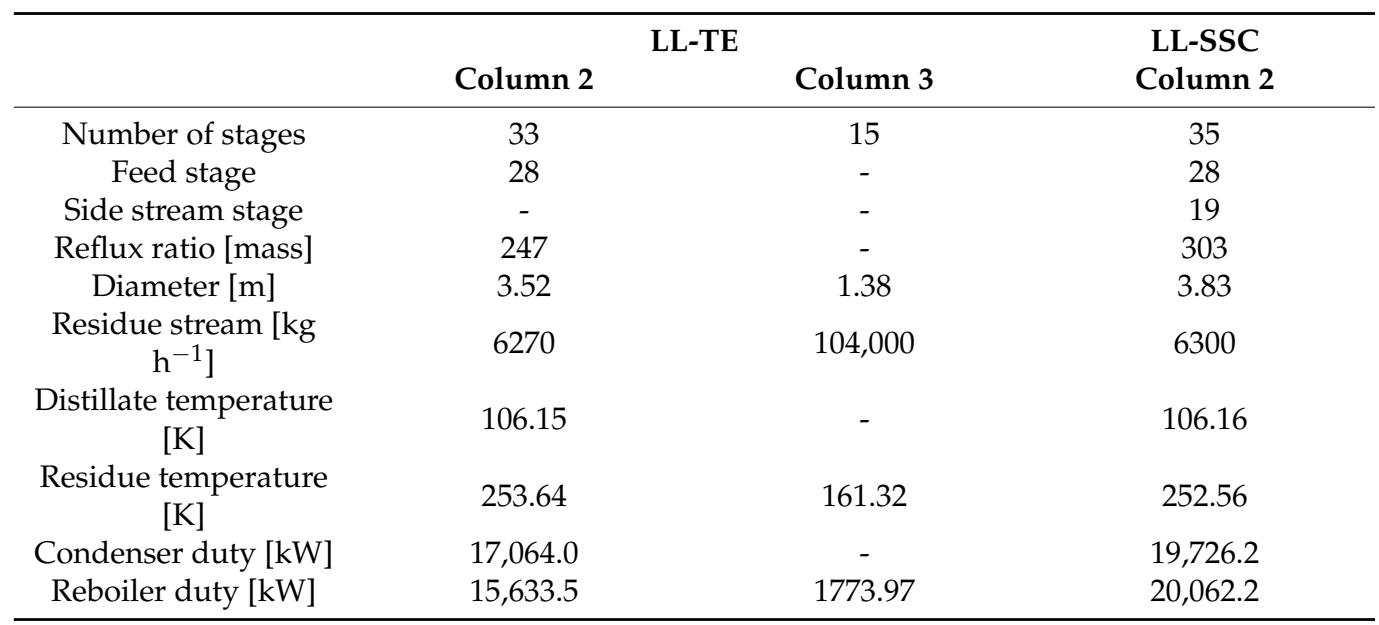

The LL-TE configuration was optimized defining the minimum liquid flowrate, connecting the second and the third column that assures the achievement of the purity targets. Also, the position of the vapor and liquid connecting streams were optimized to match the stream and column composition. In the LL-SSC, the side stream is in liquid phase located in the column section above the feed. The LL-TE configuration operates with lower duties allowing the configuration to achieve a $2 \%$ savings in the OC. On the other side the OC of the LL-SSC the configuration is $11 \%$ higher than that of the LL-DI. This penalty is a result of the fact that the separation of the three components is realized in the same column. Hence, all the heat necessary for the separation is provided at the highest temperature requiring the use of hot oil as a utility. Moreover, this configuration is further penalized by a higher 
capital cost due to the highest diameter of the column that performs the separation of FA, F and LA.

\section{Conclusions}

In the present study the separation of LA from a model solution obtained from acid hydrolysis of lignocellulosic biomass is considered. Hybrid flowsheets achieved by a combination of liquid-liquid extraction and distillation have been considered to obtain pure LA and recover a commercial grade FA stream. Furfural that is also part of the feed mixture has been chosen as extracting agent for the extraction step. The analysis of the hybrid alternatives including simple distillation columns was proved to be the first step in developing a synthesis method to predict intensified alternatives. In particular, it was determined that the liquid-liquid direct-indirect (LL-DI) alternative was the best option among the simple column alternatives. In this configuration the water stream was recovered in the first column followed by LA, FA and F. Two intensified alternatives were generated from the LL-DI. The former included a thermal coupling between the second and the third column, while the latter had one column less and F was removed through a side stream.

With regard to all the alternatives considered, the configuration with a thermal coupling has a slightly better performance in terms of operative and capitals costs but further studies are required. In particular, more configurations should be considered and other indexes than the economics should be included.

Finally, this study provides a systematic method to generate process alternatives that are expected to be competitive with respect to the benchmark case used as a reference.

Author Contributions: All three authors equally contributed to the conceptualization, validation and writing. M.E. and R.P.S. were responsible for funding acquisition and administration. All authors have read and agreed to the published version of the manuscript.

Funding: EU Horizon 2020 Marie Sklodowska-Curie RISE grant agreement No 778168.

Institutional Review Board Statement: Not applicable.

Informed Consent Statement: Not applicable.

Data Availability Statement: Not applicable.

Conflicts of Interest: The authors declare no conflict of interest.

\section{References}

1. Sengupta, D.; Pike, R.W. Chemicals from Biomass: Integrating Bioprocesses into Chemical Production Complexes for Sustainable Development; CRC Press: Boca Raton, FL, USA, 2012; ISBN 9781439878156.

2. Kelloway, A.; Daoutidis, P. Process synthesis of biorefineries: Optimization of biomass conversion to fuels and chemicals. Ind. Eng. Chem. Res. 2014, 53, 5261-5273. [CrossRef]

3. Han, J.; Murat Sen, S.; Luterbacher, J.S.; Alonso, D.M.; Dumesic, J.A.; Maravelias, C.T. Process systems engineering studies for the synthesis of catalytic biomass-to-fuels strategies. Comput. Chem. Eng. 2015, 81, 57-69. [CrossRef]

4. Trippe, F.; Fröhling, M.; Schultmann, F.; Stahl, R.; Henrich, E.; Dalai, A. Comprehensive techno-economic assessment of dimethyl ether (DME) synthesis and Fischer-Tropsch synthesis as alternative process steps within biomass-to-liquid production. Fuel Process. Technol. 2013, 106, 577-586. [CrossRef]

5. Keleman, A.; Rañó, H.G. The mexican tortilla crisis of 2007: The impacts of grain-price increases on food-production chains. Dev. Pract. 2011, 21, 550-565. [CrossRef]

6. Isikgor, F.H.; Becer, C.R. Lignocellulosic biomass: A sustainable platform for the production of bio-based chemicals and polymers. Polym. Chem. 2015, 6, 4497-4559. [CrossRef]

7. Fitzpatrick, S.W. Production of Levulinic Acid from Carbohydrate-Containing Materials. U.S. Patent 5,608,105, 4 March 1997.

8. Fitzpatrick, S. Lignocellulose Degradation to Furfural and Levulinic Acid. U.S. Patent 4,897,497, 30 January 1990.

9. Hayes, D.J.; Fitzpatrick, S.; Hayes, M.H.B.; Ross, J.R.H. The Biofine Process-Production of Levulinic Acid, Furfural, and Formic Acid from Lignocellulosic Feedstocks. In Biorefineries-Industrial Processes and Products: Status Quo and Future Directions; Kamm, B., Gruber, P.R., Kamm, M., Eds.; Wiley-VCH: Weinheim, Germany, 2006; pp. 139-164. ISBN 3527310274.

10. Waleva Turning Waste into Resource. Available online: http:/ / waleva.eu (accessed on 2 March 2021). 
11. Dibanet Development of Integrated Biomass Approaches NETwork. Available online: https://dibanet.geonardo.com (accessed on 2 March 2021).

12. Galletti, A.M.R.; Antonetti, C.; De Luise, V.; Licursi, D.; Di Nasso, N.N.O. Levulinic acid production from waste biomass. BioResources 2012, 7, 1824-1834. [CrossRef]

13. Morone, A.; Apte, M.; Pandey, R.A. Levulinic acid production from renewable waste resources: Bottlenecks, potential remedies, advancements and applications. Renew. Sustain. Energy Rev. 2015, 51, 548-565. [CrossRef]

14. Kumar, P.; Varkolu, M.; Mailaram, S.; Kunamalla, A.; Maity, S.K. Biorefinery polyutilization systems: Production of green transportation fuels from biomass. In Polygeneration with Polystorage: For Chemical and Energy Hubs; Khalilpour, K.R., Ed.; Academic Press: Cambridge, MA, USA, 2019; pp. 73-407. ISBN 9780128133064.

15. Prescient \& Strategic Intelligence. Available online: https://www.psmarketresearch.com/market-analysis/levulinic-acid-market (accessed on 30 December 2020).

16. Kumar, A.; Shende, D.Z.; Wasewar, K.L. Production of levulinic acid: A promising building block material for pharmaceutical and food industry. Mater. Today Proc. 2019, 790-793. [CrossRef]

17. Signoretto, M.; Taghavi, S.; Ghedini, E.; Menegazzo, F. Catalytic Production of Levulinic Acid (LA) from Actual Biomass. Molecules 2019, 24, 2760. [CrossRef]

18. Pyo, S.H.; Glaser, S.J.; Rehnberg, N.; Hatti-Kaul, R. Clean Production of Levulinic Acid from Fructose and Glucose in Salt Water by Heterogeneous Catalytic Dehydration. ACS Omega 2020, 5, 14275-14282. [CrossRef] [PubMed]

19. GF Biochemicals. Available online: http:/ /www.gfbiochemicals.com/company/ (accessed on 2 March 2021).

20. De, B.S.; Wasewar, K.L.; Dhongde, V. Extractive separation of protocatechuic acid using natural non-toxic solvents and conventional solvents. Chem. Data Collect. 2018, 15-16, 244-253. [CrossRef]

21. Datta, D.; Marti, M.E.; Pal, D.; Kumar, S. Equilibrium study on the extraction of levulinic acid from aqueous solution with aliquat 336 dissolved in different diluents: Solvent's polarity effect and column design. J. Chem. Eng. Data 2017, 62, 3-10. [CrossRef]

22. Isoni, V.; Kumbang, D.; Sharratt, P.N.; Khoo, H.H. Biomass to levulinic acid: A techno-economic analysis and sustainability of biorefinery processes in Southeast Asia. J. Environ. Manag. 2018, 214, 267-275. [CrossRef] [PubMed]

23. Tiong, Y.W.; Yap, C.L.; Gan, S.; Yap, W.S.P. Kinetic study on oil palm biomass conversion to levulinic acid via indium trichlorideionic liquids. IOP Conf. Ser. Earth Environ. Sci. 2018, 164, 012007. [CrossRef]

24. Licursi, D.; Antonetti, C.; Martinelli, M.; Ribechini, E.; Zanaboni, M.; Raspolli Galletti, A.M. Monitoring/characterization of stickies contaminants coming from a papermaking plant-Toward an innovative exploitation of the screen rejects to levulinic acid. Waste Manag. 2016, 49, 469-482. [CrossRef] [PubMed]

25. Kang, S.; Fu, J.; Zhang, G. From lignocellulosic biomass to levulinic acid: A review on acid-catalyzed hydrolysis. Renew. Sustain. Energy Rev. 2018, 94, 340-362. [CrossRef]

26. Pratama, A.P.; Rahayu, D.U.C.; Krisnandi, Y.K. Levulinic acid production from delignified rice husk waste over manganese catalysts: Heterogeneous versus homogeneous. Catalysts 2020, 10, 327. [CrossRef]

27. Barla, M.K.; Velagala, R.R.; Minpoor, S.; Madduluri, V.R.; Srinivasu, P. Biomass derived efficient conversion of levulinic acid for sustainable production of $\gamma$-valerolactone over cobalt based catalyst. J. Hazard. Mater. 2020, 405, 123335. [CrossRef]

28. López-Aguado, C.; Paniagua, M.; Melero, J.A.; Iglesias, J.; Juárez, P.; Granados, M.L.; Morales, G. Stable continuous production of $\gamma$-valerolactone from biomass-derived levulinic acid over zr-al-beta zeolite catalyst. Catalysts 2020, 10, 678. [CrossRef]

29. Laitinen, A.T.; Penttilä, K.J.T.; Kaunisto, J.M. Physical solvent extraction of levulinic acid from dilute aqueous solution with 2-methyltetrahydrofuran. Sep. Sci. Technol. 2016, 465-473. [CrossRef]

30. Brouwer, T.; Blahusiak, M.; Babic, K.; Schuur, B. Reactive extraction and recovery of levulinic acid, formic acid and furfural from aqueous solutions containing sulphuric acid. Sep. Purif. Technol. 2017, 185, 186-195. [CrossRef]

31. Nikitin, E.D.; Popov, A.P.; Bogatishcheva, N.S.; Faizullin, M.Z. Critical temperatures and pressures, heat capacities, and thermal diffusivities of levulinic acid and four n-alkyl levulinates. J. Chem. Thermodyn. 2019, 135, 233-240. [CrossRef]

32. Ariba, H.; Wang, Y.; Devouge-Boyer, C.; Stateva, R.P.; Leveneur, S. Physicochemical Properties for the Reaction Systems: Levulinic Acid, Its Esters, and $\gamma$-Valerolactone. J. Chem. Eng. Data 2020, 65, 3008-3020. [CrossRef]

33. Tacchini, E.; Casson Moreno, V.; Tugnoli, A.; Cozzani, V. Technical-economic analysis of processes for the production of levulinic acid. Chem. Eng. Trans. 2020, 80, 277-282.

34. Miranda, J.C.C.; Ponce, G.H.S.F.; Neto, J.M.; Concha, V.O.C. Simulation and Feasibility Evaluation of a Typical Levulinic Acid (LA) Plant using Biomass as Substrate. Chem. Eng. Trans. 2019, 74, 901-906. [CrossRef]

35. Nhien, L.C.; Long, N.V.D.; Lee, M. Design and optimization of the levulinic acid recovery process from lignocellulosic biomass. Chem. Eng. Res. Des. 2016, 107, 126-136. [CrossRef]

36. Alcocer-García, H.; Segovia-Hernández, J.G.; Prado-Rubio, O.A.; Sánchez-Ramírez, E.; Quiroz-Ramírez, J.J. Multi-objective optimization of intensified processes for the purification of levulinic acid involving economic and environmental objectives. Chem. Eng. Process. Process Intensif. 2019, 136, 123-137. [CrossRef]

37. Errico, M. Process synthesis and intensification of hybrid separations. In Process Synthesis and Process Intensification; Rong, B.G., Ed.; De Gruyter: Berlin, Germany; Boston, MA, USA, 2017.

38. Kiss, A.A. Distillation technology—Still young and full of breakthrough opportunities. J. Chem. Technol. Biotechnol. 2014, 89, 479-498. [CrossRef]

39. Seibert, F. A Method for Recovering Levulinic Acid; World Intellectual Property Organization: Geneva, Switzerland, 2009. 
40. Errico, M.; Rong, B.G.; Tola, G.; Turunen, I. A method for systematic synthesis of multicomponent distillation systems with less than N-1 columns. Chem. Eng. Process. Process Intensif. 2009, 48, 907-920. [CrossRef]

41. Thompson, R.W.; King, C.J. Systematic synthesis of separation schemes. AIChE J. 1972, 18, 941-948. [CrossRef]

42. King, C.J. Separation Processes; McGraw-Hil: New York, NY, USA, 1980.

43. Errico, M.; Pirellas, P.; Torres-Ortega, C.E.; Rong, B.G.; Segovia-Hernandez, J.G. A combined method for the design and optimization of intensified distillation systems. Chem. Eng. Process. Process Intensif. 2014, 85, 69-76. [CrossRef]

44. Errico, M.; Rong, B.G. Systematic synthesis of intensified distillation systems. In Process Intensification in Chemical Engineering: Design Optimization and Control; Springer: Cham, Switzerland, 2016; pp. 35-64. ISBN 9783319283920.

45. Rong, B.G. Synthesis of dividing-wall columns (DWC) for multicomponent distillations-A systematic approach. Chem. Eng. Res. Des. 2011, 89, 1281-1294. [CrossRef]

46. Errico, M.; Rong, B.G.; Torres-Ortega, C.E.; Segovia-Hernandez, J.G. The importance of the sequential synthesis methodology in the optimal distillation sequences design. Comput. Chem. Eng. 2014, 62, 1-9. [CrossRef]

47. ICIS. Chemical Profile: Formic Acid. Available online: https://www.icis.com/explore/resources/news/2006/07/26/2015258 / chemical-profile-formic-acid/ (accessed on 6 January 2021).

48. Aspen Plus V.11. Available online: https://www.aspentech.com/en/products/pages/aspen-process-manual (accessed on 18 January 2021).

49. Turton, R.; Shaeiwitz, J.A.; Bhattacharyya, D.; Whiting, W.B. Analysis, Synthesis, and Design of Chemical Processes; Prentice Hall PTR: Upper Saddle River, NJ, USA, 2018; ISBN1 0135705657. ISBN2 9780135705650.

50. Economic Indicators, Chemical Engineering, December 2020. Available online: https:/ /www.chemengonline.com/economicindicators-cepci/ ?printmode=1 (accessed on 5 February 2021). 